\title{
The Effect of Body Mass Index On The Outcomes of
}

\section{Open Simple Prostatectomy}

\author{
Ender Cem Bulut ${ }^{1^{\star}}$, Kasım Ertaş ${ }^{2}$, Murat Yavuz Koparal ${ }^{3}$, Serhat Çetin ${ }^{4}$ \\ ${ }^{1}$ Department of Urology, Van Training and Research Hospital, Van, Turkey \\ ${ }^{2}$ Department of Urology, School of Medicine, Yüzüncü Yıl University, Van, Turkey \\ ${ }^{3}$ Department of Urology, Recep Tayyip Erdogan University Training and Research Hospital, Rize, Turkey \\ ${ }^{4}$ Department of Urology, School of Medicine, Gazi University, Ankara, Turkey
}

\begin{abstract}
Simple prostatectomy remains the gold standard treatment for patients with severe lower urinary tract symptoms (LUTS) and patients with enlarged prostate. Obesity, defined as a body mass index over $30 \mathrm{~kg} / \mathrm{m} 2$ by the World Health

Organization (WHO), is associated with some perioperative complications. This study aims to investigate the effects of obesity on the outcomes of open simple prostatectomy.

The study includes 72 patients that underwent open simple prostatectomy. We compared the treatment outcomes of 49 patients with a body mass index $(\mathrm{BMI})<30 \mathrm{~kg} / \mathrm{m} 2$ and 16 patients with a $\mathrm{BMI}>30 \mathrm{~kg} / \mathrm{m} 2$. We compared the two groups in terms of change in International Prostate Symptom Score (IPSS), change in uroflowmetry maximum flow rate (Qmax), operation time, intraoperative blood loss, transfusion requirements.

The median of change in IPSS scores was $16(11-30)$ for the group where BMI $<30 \mathrm{~kg} / \mathrm{m} 2$ and $15.5(10-20)$ for the group where BMI $>30 \mathrm{~kg} / \mathrm{m} 2$. This difference was not statistically significant $(\mathrm{p}=0.383)$. The mean duration of operation was $90.61 \pm 17.45$ minutes for patients with $\mathrm{BMI}<30 \mathrm{~kg} / \mathrm{m} 2$ and $121.87 \pm 18.78$ minutes for patients with a BMI $>30 \mathrm{~kg} / \mathrm{m} 2$. The difference between the two groups was statistically significant $(\mathrm{p}<0.001)$. The median of blood loss was $450(200-700) \mathrm{cc}$ for the BMI $<30 \mathrm{~kg} / \mathrm{m} 2$ group and $725(550-850)$ cc for the BMI $>30 \mathrm{~kg} / \mathrm{m} 2$ group, and this difference was statistically significant $(\mathrm{p}<0.001)$. However, the blood transfusion requirements of the two groups were statistically similar $(\mathrm{p}=0.885)$. Open simple prostatectomy is very important technic in the treatment of BPH patients with enlarged prostates. Despite obesity is associated with a prolonged operation and increased transfusion rates in open simple prostatectomy, it can still be considered a safe treatment method.
\end{abstract}

Key Words: Benign prostatic hyperplasia, body mass index, prostatectomy, obesity

\section{Introduction}

There are several effective treatment methods for male patients with mild lower urinary tract symptoms (LUTS) or with benign prostatic hyperplasia (BPH) with a small prostate size; however, simple prostatectomy remains the gold standard treatment for patients with severe LUTS and patients with a prostate larger than 80 grams. Indications for simple prostatectomy include urinary retention requiring intermittent catheterization, medical therapy-resistant LUTS, persistant hematuria, bladder stones, or $\mathrm{BPH}$ related chronic kidney disease. Open simple prostatectomy is preferable to transurethral prostate resection in patients with a prostate greater than $80 \mathrm{~g}$, patients with accompanying bladder pathologies that also require open surgery, patients who are planned for simultaneous hernia repair, or patients with orthopedic pathologies that prevent lithotomy position (1). The disadvantages of open prostatectomy include requiring incisions, transfusion-requiring blood loss, sphincter or rectal injury, prolonged hospital stay, and prolonged catheterization (2).

There are several modern techniques that have yielded positive results such as holmium laser enucleation of the prostate (HoLEP) and the potassium-titanyl-phosphate (KTP) laser methods (3). Despite its proven efficacy, these methods have certain disadvantages such as the requirement of special equipment, the steep learning curve, high costs, and the requirement of tissue morcellation (4).

The World Health Organization (WHO) defines obesity as having a body mass index (BMI) 30 $\mathrm{kg} / \mathrm{m} 2$ or higher (5). Due to its increasing frequency resulting from unbalanced nutrition and

\section{${ }^{*}$ Corresponding Author: Ender Cem Bulut, Department of Urology, Van Training and Research Hospital, Van, Turkey}

E-mail: endercem@hotmail.com, Telephone: +90 (533) 9280015

ORCID ID: Ender Cem Bulut: 0000-0002-5002-5471, Kasım Ertaş: 0000-0003-4300-1399, Murat Yavuz Koparal: 0000-0002-8347-5727, Serhat Çetin: 0000-0001-5450-5168

Received: 30.04.2020, Accepted: 24.08.2020 
inadequate physical activity, obesity has become a global public health problem (6). Several urology studies reported that obesity is associated with increased postoperative complications such as cardiovascular events, wound infections, deep vein thrombosis (DVT), and wound dehiscence, but other studies report obesity does not affect treatment outcomes (7-9).

In this study, we evaluated the effects of obesity on the peri- and postoperative outcomes of open simple prostatectomy.

\section{Materials and Methods}

We retrospectively evaluated data of 72 patients that underwent open simple prostatectomy for benign prostatic hyperplasia (BPH) between September 2016 and January 2020. We excluded 7 patients that underwent transrectal prostate needle biopsy before the operation or whose surgical pathologies are reported as malignancy.

The demographic, and pre- and postoperative data of the remaining 65 patients were recorded. The patients were divided into two groups depending on body mass index: BMI $\geq 30 \mathrm{~kg} / \mathrm{m}^{2}$ and BMI $<$ $30 \mathrm{~kg} / \mathrm{m}^{2}$.

The preoperative age, PSA level, and preoperative IPSS scores were recorded for all subjects. Also, all subjects underwent a complete blood count (CBC). The subjects' prostate sizes were routinely evaluated before the operation through urinary ultrasonography performed by the radiology department. The duration of operation and intraoperative blood loss were recorded. A CBC was performed within one hour after the surgery. In postoperative weeks 4-6, the patients' IPSS scores were determined and all patients underwent uroflowmetry.

The two groups were compared in terms of age, PSA levels, preoperative IPSS scores, prostate sizes as measured by urinary USG, preoperative hemoglobin and hematocrit values, duration of operation, intraoperative blood loss, postoperative hemoglobin and hematocrit values, length of hospital stay, and IPSS scores in postoperative weeks 4-6.

Surgical Technique

After appropriate anesthesia, the patient was placed in a $5^{\circ}$ or $10^{\circ}$ degree Trendelenburg position. The relevant anatomical region was prepared for surgery and an $18 \mathrm{~F}$ urethral catheter was placed into the bladder. Following the Pfannenstiel incision, the bladder was deperitonized and the prostate adenomas were transvesically enucleated with an index finger. Surgical sutures were placed to the bladder neck to control bleeding and the bladder was primarily closed. A surgical drain was inserted into the retropubic space and the anatomical layers were adequately closed.

Statistical Analysis: The normal distribution of continuous variables was evaluated by visually (histogram and probability plots) and analytical methods (Kolmogorov-Smirnov/Shapiro-Wilk tests). In the descriptive findings, categorical variables are given as numbers (percent); continuous variables were presented with mean \pm standard deviation for normal scattering data and median (minimum-maximum) for normal nonscattering data. For the categorical variables, statistical difference between the groups was determined by Fisher's exact test. For the continuous variables, statistical difference between the groups was determined by Mann-Whitney U and independent t-test. Statistical significance was accepted as $\mathrm{p}<0.05$. $\mathrm{R}$ software version 3.6.3 was used for statistical analysis of research data.

\section{Results}

There were 49 subjects in group 1 and 16 subjects in group 2. The two groups were not significantly different regarding the following preoperative parameters: prostate size as measured transabdominally, IPSS score, Qmax $(\mathrm{mL} / \mathrm{s})$, and post-void residual (PVR) volume (cc). (Table 1) Among the perioperative parameters, the mean duration of operation was significantly longer in group 2. The mean operation time was $90.61 \pm$ 17.45 minutes for group 1 and $121.87 \pm 18.78$ minutes for group 2. This difference was statistically significant $(\mathrm{p}<0.001)$. The mean perioperative blood loss was significantly higher in group 2. The median of intraoperative blood loss values were 450 (200-700) ccs for group 1 and 725 (550-850) ccs for group 2 ( $\mathrm{p}<0.001)$.

The two groups were not significantly different regarding the following postoperative parameters: IPSS score, Qmax (mL/s), PVR (cc), drainage, catheterization, and length of hospital stay. (Table 2)

The median of changes in $\mathrm{Hb}$ were 2.5 (1.0-3.6) for group 1 and 3.7 (2.3-5.6) for group 2, and this difference was statistically significant $(\mathrm{p}<0.001)$. The number of patients that required blood transfusions was $10(20.4 \%)$ for group 1 and 3 $(18.7 \%)$ for group two; however, this difference was not statistically significant $(\mathrm{p}=0.885)$. 
Table 1. Pre- and Perioperative Parameters

\begin{tabular}{lccc}
\hline Pre- and Perioperative Parameters & & & \\
& $<30 \mathrm{~kg} / \mathrm{m} 2$ & $\geq 30 \mathrm{~kg} / \mathrm{m} 2$ & \\
Body Mass Index & Mean \pm SD & Mean \pm SD & p value \\
& Median (Minimum- & Median (Minimum- & \\
& $140.20 \pm 34.90$ & $144.68 \pm 34.95$ & $0.556^{*}$ \\
Prostate Size & $23.02 \pm 4.42$ & $22.06 \pm 3.19$ & $0.427^{*}$ \\
IPSS & $6.32 \pm 3.76$ & $6.81 \pm 3.48$ & $0.649 *$ \\
Qmax (mL/s) & $160(30-425)$ & $165(20-200)$ & $0.703^{* *}$ \\
PVR (cc) & $90.61 \pm 17.45$ & $121.87 \pm 18.78$ & $<0.001^{*}$ \\
Duration of the operation (min) & $450(200-700)$ & $725(550-850)$ & $<$ \\
Blood Loss (cc) & & $0.001^{* *}$ \\
\hline
\end{tabular}

SD: Standard Deviation, IPSS: International Prostate Symptom Score, PVR: post-void residual volume *Student's t-test **Mann-Whitney U test

Table 2. Postoperative Parameters

\begin{tabular}{|c|c|c|c|}
\hline \multicolumn{4}{|l|}{ Postoperative Parameters } \\
\hline Body Mass Index & $\begin{array}{c}<30 \mathrm{~kg} / \mathrm{m} 2 \\
\text { Mean } \pm \mathrm{SD} \\
\text { Median (Minimum- } \\
\text { Maximum) }\end{array}$ & $\begin{array}{c}\geq 30 \mathrm{~kg} / \mathrm{m} 2 \\
\text { Mean } \pm \text { SD } \\
\text { Median (Minimum- } \\
\text { Maximum) }\end{array}$ & $\mathrm{p}$ value \\
\hline IPSS & $6(1-14)$ & $6.5(3-13)$ & $0.549 * *$ \\
\hline Change in IPSS & $16(11-30)$ & $15.5(10-20)$ & $0.381 * *$ \\
\hline $\mathrm{Qmax}(\mathrm{mL} / \mathrm{s})$ & $22(10-30)$ & $20.5(14-25)$ & $0.305^{* *}$ \\
\hline Change in $\mathrm{Qmax}(\mathrm{mL} / \mathrm{s})$ & $15(9-26)$ & $14(7-19)$ & $0.095^{* *}$ \\
\hline PVR (cc) & $25(0-65)$ & $32.5(5-40)$ & $0.327 * *$ \\
\hline Change in Hemoglobin & $2.5(1.0-3.6)$ & $3.7(2.3-5.6)$ & $<0.001 * *$ \\
\hline $\begin{array}{l}\text { Patients that required blood } \\
\text { transfusion }\end{array}$ & $10(20.4 \%)$ & $3(18.8 \%)$ & $0.885^{* * *}$ \\
\hline Surgical Drain Duration (days) & $5(4-6)$ & $5(4-7)$ & $0.907 * *$ \\
\hline Duration of Catheterization (days) & $7(7-9)$ & $7(7-9)$ & $0.648 * *$ \\
\hline Length of Hospital Stay (days) & $7(7-10)$ & $7(7-10)$ & $0.590 * *$ \\
\hline
\end{tabular}

IPSS: International Prostate Symptom Score

**Mann-Whitney U test ***Pearson's Chi Square test

\section{Discussion}

If a patient is preoperatively determined to have a prostate size larger than $80 \mathrm{~mL}$, guidelines recommend an open simple prostatectomy(10). Open prostatectomy also must be considered in certain cases where open surgery is inevitable, such as when a patient has comorbidities like ankylosis. Open prostatectomy is also recommended for patients who cannot be positioned for TUR-P and in complicated urethral diseases such as urethral trauma or hypospadias that requires repeated interventions $(1,10)$.

There are numerous studies that compare open simple prostatectomies with minimally invasive methods (laparoscopic simple prostatectomy and robotic simple prostatectomy), or open radical prostatectomy, laparoscopic radical prostatectomy and robot-assisted laparoscopic radical prostatectomy, and that investigate the effects of obesity on the outcomes of these surgeries. To the best of our knowledge, our study is the first study to investigate the effect of obesity on open simple prostatectomy outcomes.

In their study, Baumert et al. compared laparoscopic and open simple prostatectomies and compared the duration of operation and blood loss outcomes of the two groups. They found the mean duration of operation to be $108 \pm 27$ minutes and the mean blood loss to be $330 \pm 207$ ccs for open simple prostatectomy (11). Other studies by Porpiglia et al. and McCullough et al.

East J Med Volume:25, Number:4, October-December/2020 
that compare laparoscopic and open simple prostatectomies found the mean duration of open simple prostatectomy to be $106.92 \pm 29.9 \mathrm{~min}$ and $54.7 \pm 19.7 \mathrm{~min}$, and mean blood loss to be $531.54 \pm 191.13 \mathrm{ccs}$ and $400 \mathrm{ccs}$ (300-600), respectively(12,13). The findings of these studies regarding the duration of operation and blood loss are similar to our results of non-obese patients; however, none of these studies investigated the effects of obesity on perioperative outcomes.

Knipper et al. investigated the effects of obesity on the outcomes of open and robot-assisted laparoscopic radical prostatectomies. They evaluated data from 35757 patients and found the blood transfusion rate to be $10.6 \%$ for obese patients and $8.8 \%$ for non-obese patients. They found that obesity significantly increased blood transfusion requirements (14). Similarly, Chang et al. investigated the factors affecting blood loss and blood transfusion requirements in 436 open radical prostatectomy patients. They evaluated age, ASA score, PSA level, Gleason score, body mass index, and preoperative hematocrit values as preoperative parameters and found that only obesity significantly increased blood loss and transfusion requirement (15). Johnson et al. investigated the effects of obesity on the outcomes of radical prostatectomy in 4657 patients and found that obesity significantly increased the transfusion requirement(16). All of the studies mentioned above evaluated this increased blood loss and transfusion requirement as a result of the increased technical difficulties in radical prostatectomy that are associated with obesity and that obesity is an independent risk factor for intra- and postoperative complications. There are also studies that investigate the effect of obesity on renal interventions. Isoglu et al. investigated the effect of obesity on percutaneous nephrolithotomy, Marc et al. on open and laparoscopic nephrectomy, and Uguz et al. on duration of operation and blood loss in donor nephrectomy. While none of these studies found a difference in operation time, Feder et al. reported that obesity increased blood loss (17-19).

We also think that obesity complicates the application of surgical techniques and the ideal exposure cannot be achieved in obese patients undergoing open simple prostatectomy. We assume that this condition, together with the surgeon not being able to work comfortably, translates into a prolonged operation. Nonanatomical dissection, a prolonged operation, and that obesity is an independent risk factor for surgical complications may increase in the transfusion rates.

In their study, Baumert et al. compared the outcomes of laparoscopic and open simple prostatectomies by comparing pre- and postoperative IPSS scores and Qmax $(\mathrm{mL} / \mathrm{s})$ values. They also recorded the body mass indices of the patients, but did not include it as a parameter for analysis. They reported that after the open simple prostatectomy, the mean IPSS score decreased from $24.7 \pm 7.8$ to $8.2 \pm 2.7$ and the mean Qmax increased from $8.7 \pm 2.3$ to 34.9 \pm 13.3 (11). Demir et al. and Porpiglia et al. similarly compared laparoscopic and open simple prostatectomies and found that the mean IPSS scores of open simple prostatectomy patients decreased from $19.9 \pm 5.5$ to $7.1 \pm 2.1$ and from $20.9 \pm 7.0$ to $6.7 \pm 3.3$, and the mean $\mathrm{Qmax}$ values increased from $6.4 \pm 2.4$ to $21.6 .9 \pm 3.9$ and from $17.7 \pm 7.7$ to $25.4 \pm 7.3(12,20)$. Demir et al. also evaluated pre- and postoperative postvoid residual volumes of open simple prostatectomy patients and found that it decreased from $185.0 \pm 121.4$ to $35.5 \pm 13.2$ (20). Although the results in all of these studies are similar those of our study, none of the aforementioned studies investigated the effect of obesity on the indicated parameters. We believe that it is possible to achieve the desired results with open simple prostatectomy performed with the proper surgical technique in obese patients, despite being challenging.

The first limitation of our study is its retrospective design. The second limitation is that the long-term outcomes of the patients could not be evaluated, and thus, the two groups could not be compared. Body mass index can be insufficient in defining obesity in certain individuals (e.g. patients with a large muscle mass). However, the available database only allows the evaluation of the body mass index of the patients. Hence, other anthropometric parameters such as waist circumference or waist-to-hip ratio could not be evaluated.

Open simple prostatectomy is still important in the treatment of $\mathrm{BPH}$ patients with enlarged prostates. We conclude that obesity is associated with a prolonged operation and increased transfusion rates in open simple prostatectomy. Nevertheless, it can still be considered a safe treatment method. Further studies with larger patient groups are needed to evaluate the effects of obesity on open simple prostatectomy. 


\section{References}

1. Han M, Partin A. Retrograde and suprapubic open prostatectomy. Wein AJ, Kavoussi LR, Novick AC, Partin AW, Peters CA. CampbellWalsh Urology. Philadelphia: Saunders Elsevier. 20122695-703.

2. Adam C, Hofstetter A, Deubner J, et al. Retropubic transvesical prostatectomy for significant prostatic enlargement must remain a standard part of urology training. Scandinavian journal of urology and nephrology 2004; 38: 472476.

3. Gilling PJ, Cass CB, Cresswell MD, Fraundorfer MR. Holmium laser resection of the prostate: preliminary results of a new method for the treatment of benign prostatic hyperplasia. Urology 1996; 47: 48-51.

4. Kuebker JM, Miller NL. Holmium laser enucleation of the prostate: patient selection and outcomes. Current urology reports 2017; 18: 96.

5. Kuczmarski RJ, Carroll MD, Flegal KM, Troiano RP. Varying body mass index cutoff points to describe overweight prevalence among US adults: NHANES III (1988 to 1994). Obesity research. 1997; 5: 542-548.

6. Calvert RC, Burgess NA. Urolithiasis and obesity: metabolic and technical considerations. Current opinion in urology 2005; 15: 113-117.

7. Koo B, Burtt G, Burgess N. Percutaneous stone surgery in the obese: outcome stratified according to body mass index. BJU international 2004; 93 : 1296-1299.

8. Alyami FA, Skinner TA, Norman RW. Impact of body mass index on clinical outcomes associated with percutaneous nephrolithotomy. Canadian Urological Association Journal 2013; 7: E197.

9. Kapoor A, Nassir A, Chew B, Gillis A, Luke P, Whelan P. Comparison of laparoscopic radical renal surgery in morbidly obese and non-obese patients. Journal of endourology 2004; 18: 657660.

10. Gravas S, Cornu J, Gacci M, et al. Management of non-neurogenic male lower urinary tract symptoms (LUTS), incl. benign prostatic obstruction (BPO) 2019.
11. Baumert H, Ballaro A, Dugardin F, Kaisary A. Laparoscopic versus open simple prostatectomy: a comparative study. The Journal of urology. 2006;175:1691-4.

12. Porpiglia F, Terrone C, Renard J, et al. Transcapsular adenomectomy (Millin): a comparative study, extraperitoneal laparoscopy versus open surgery. European urology 2006; 49: 120-126.

13. McCullough TC, Heldwein FL, Soon SJ, et al. Laparoscopic versus open simple prostatectomy: an evaluation of morbidity. Journal of endourology 2009; 23: 129-134.

14. Knipper S, Mazzone E, Mistretta FA, et al. Impact of Obesity on Perioperative Outcomes at Robotic-assisted and Open Radical Prostatectomy: Results From the National Inpatient Sample. Urology 2019; 133: 135-144.

15. Chang SS, Duong DT, Wells N, Cole EE, Smith JA, Cookson MS. Predicting blood loss and transfusion requirements during radical prostatectomy: the significant negative impact of increasing body mass index. The Journal of urology 2004; 171: 1861-1865.

16. Johnson SC, Packiam VT, Golan S, Cohen AJ, Nottingham CU, Smith ND. The effect of obesity on perioperative outcomes for open and minimally invasive prostatectomy. Urology. 2017; 100: 111-116.

17. Isoglu CS, Suelozgen T, Boyacioglu H, Koc G. Effects of body mass index on the outcomes of percutaneous nephrolithotomy. International braz j urol 2017; 43: 698-703.

18. Feder MT, Patel MB, Melman A, Ghavamian R, Hoenig DM. Comparison of open and laparoscopic nephrectomy in obese and nonobese patients: outcomes stratified by body mass index. The Journal of urology 2008; 180: 79-83.

19. Uguz A, Unsal M, Unalp O, et al. Is a high body mass index still a risk factor for complications of donor nephrectomy? Paper presented at: Transplantation proceedings, 2015.

20. Demir A, Günseren KÖ, Kordan Y, Yavaşçaoğlu I, Vuruşkan BA, Vuruşkan H. Open vs laparoscopic simple prostatectomy: a comparison of initial outcomes and cost. Journal of endourology 2016; 30: 884-889. 